\title{
Thoracic surgery in Slovenia
}

\section{Tomaž Štupnik ${ }^{1,2 \wedge}$}

${ }^{1}$ Department of Thoracic Surgery, University Medical Centre Ljubljana, Ljubljana, Slovenia; ${ }^{2}$ Medical Faculty, University of Ljubljana, Ljubljana, Slovenia

Correspondence to: Tomaž Štupnik. Department of Thoracic Surgery, University Medical Centre Ljubljana, Zaloska 7, 1000 Ljubljana, Slovenia.

Email: tomaz.stupnik@kclj.si.

\begin{abstract}
Slovenia is a small country in the Southeastern part of Europe with a Gross Domestic Product slightly below the European average. There are eleven board-certified thoracic surgeons and four residents, dealing with roughly 2,500 thoracic cases per year. Thoracic Surgery in Slovenia is a challenging surgical specialty covering a wide range of problems such as lung cancer and other thoracic cancers, diseases of the esophagus, airway surgery, interventional endoscopy, pediatric thoracic surgery, lung transplantation, and even some nonthoracic problems such as surgery of the thyroid and parathyroid. Slovenian patients certainly enjoy the privilege of having free access to almost everything contemporary thoracic surgery can offer, including the most complex and least invasive procedures. In 2008 Slovenia was the first country in South-eastern Europe to adopt video-assisted thoracoscopic surgery (VATS) to treat lung cancer and other malignant diseases. It has also played an essential role in spreading the technique to neighboring countries. Slovenia also has a very successful lung transplantation program. On the other hand, most of the infrastructure is outdated, with both university hospitals built in the 1970s unable to provide a very comfortable hospital stay or increase their operating room capacities to meet the increased demand, thus waiting times for procedures of lesser priority, such as laparoscopic fundoplication and thyroidectomy became unacceptably long.
\end{abstract}

Keywords: Thoracic surgery; lung surgery; lung transplantation; esophageal surgery; pediatric thoracic surgery; interventional endoscopy; Slovenia

Submitted Jul 18, 2021. Accepted for publication Nov 02, 2021.

doi: $10.21037 /$ jtd-21-1172

View this article at: https://dx.doi.org/10.21037/jtd-21-1172

\section{Introduction}

Slovenia is a small country in the Southeastern part of Europe with an estimated population of 2.1 million and a low population density $\left(101\right.$ per $\left.\mathrm{km}^{2}\right)$. It borders Austria, Hungary, Italy, and Croatia (Figure 1) and is usually considered part of a diverse group of 10 Balkan countries: Slovenia, Croatia, Serbia, Bosnia \& Hercegovina, Kosovo, Albania, Montenegro, Macedonia, Romania, and Bulgaria.

Ljubljana is the Slovenian capital city with a population of approximately 250,000 . The $2^{\text {nd }}$ largest city is Maribor, with around 100,000 inhabitants and a medical faculty founded in 2003.
In 1991, Slovenia became the first republic to separate from the Socialist Federal Republic of Yugoslavia and become an independent sovereign state. Various economic and social reforms were then implemented. Slovenia became an European Union (EU) and NATO member in 2004 and entered the Euro $(€)$ zone in 2007.

Life expectancy at birth was 84.3 years for women and 78.2 years for men in 2016, slightly above the EU average (83.7 and 78.2 years, respectively).

The Slovenian healthcare system is a conservative health care model financed through a mandatory insurance program called the Health Insurance Institute of Slovenia

^ ORCID: 0000-0002-9019-806X. 


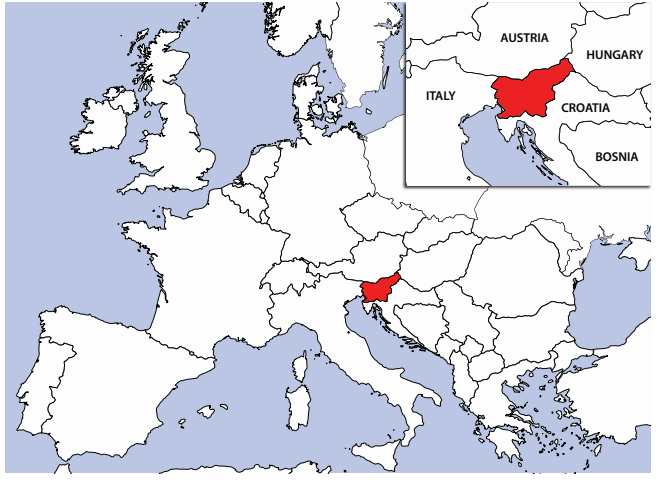

Figure 1 Slovenia in Europe.

(HIIS), with contributions paid by employers and employees. The state fund fully covers most medical services such as treatments, prescription drugs, and hospitalization. Inpatient hospital care is provided through 30 mainly public hospitals, with a few highly specialized institutions providing tertiary care. Payment for acute inpatient care is based on diagnosis-related groups (DRG).

\section{The history of thoracic surgery in Slovenia}

Thoracic surgery in Slovenia started to develop after the $2^{\text {nd }}$ World War. A visiting thoracic team from Ljubljana had performed surgeries in two remote tuberculosis sanatoriums (Golnik and Topolšica) twice a week until the 1970s when thoracic surgery moved in the two newly built university medical centers (UMC) buildings in Ljubljana and Maribor. The two tuberculosis sanatoriums were transformed into hospitals dedicated to pulmonary diseases and lung cancer diagnostics (1).

In 2006 one of the thoracic surgeons left UMC Ljubljana and opened the third thoracic center at Golnik, providing a publicly funded private practice.

\section{Thoracic education}

The pioneers of thoracic surgery in Slovenia were general surgeons who learned the trade from thoracic surgeons of the Allied Forces during the $2^{\text {nd }}$ World War and then developed it in their hospitals.

The next generations of thoracic surgeons first completed a full general surgery residency with a board exam followed by dedicated thoracic training at their thoracic departments, sometimes also in the foreign thoracic centers.

Thoracic surgery as a separate residency was introduced in 2000 by the government and the Slovenian Medical Chamber. So far, seven thoracic surgeons have completed this integrated 6-year program. After more than 20 years, it is evident that the thoracic residency program is outdated, inadequate, full of inconsistencies and desperately needs a major revision. For example, a resident must complete ten pneumonectomies but only 15 pulmonary lobectomies, five of which should be sleeve resections. Only 15 minor pulmonary resections are required, five of which must be anatomical segmental resections or wedge resections and ten metastasectomies. Video-assisted thoracoscopic surgery (VATS) training is limited to 15 mandatory procedures of any kind.

In 2017, Slovenian Medical Chamber reduced mandatory thoracic rotation at UMC Ljubljana from 15 to 2 months. This change may profoundly affect the future of thoracic surgery since out of the three centers (UMC Ljubljana, UMC Maribor, and Golnik), only UMC Ljubljana is scheduling thoracic procedures every day of the week and provides truly $24 / 7$ thoracic surgery in the country.

It is also worth noting that thoracic and cardiovascular surgery are two separate residencies in Slovenia that share only the 2-year common trunk and a few months of cardiac and thoracic rotation. This lack of cross-over training reduces the capacity of thoracic surgeons to perform complex vascular reconstructions of pulmonary vessels or extensive thoracic resections involving great vessels. On the other hand, it also slows down the adoption of minimally invasive techniques and VATS in cardiovascular surgery.

\section{Health care system and funding}

Since 1992, Slovenia has had a Bismarck-type social insurance system based on a single insurer and mandatory statutory health insurance, which is fully regulated by national legislation and administered by the Health Insurance Institute of Slovenia (HIIS).

With a nominal per-capita gross domestic product (GDP) of $\$ 27.450$, only $\$ 2.200$ (8.3\% of GDP) is spent on health care. For comparison, EU countries with the highest GDP, such as Denmark, Sweden, France, or Germany, spend almost twice that amount on health care: $\$ 4,000-\$ 5,000$ (>10\% of GDP).

Because of scarce resources, Slovenia is struggling to provide free health care for its citizens. Medical procedures of a lesser priority are often paid out of pocket, and waiting times for some diagnostic and therapeutic procedures have climbed beyond unacceptable. The current waiting time for 
laparoscopic fundoplication in UMC Ljubljana is 6 years and over 3 years for thyroidectomy.

However, thoracic cancer care is kept within a reasonable timeframe with an estimated average time of $2-3$ months elapsed from the first CT scan to the start of any treatment. There is still no comprehensive and continuous system for monitoring and improving the quality of public health services in Slovenia.

Inpatient hospital care is provided through 30 mainly public hospitals: 10 general hospitals, 2 university hospitals, 5 mental health hospitals, and 13 specialized hospitals (3 private). Some highly specialized institutions provide tertiary care, such as University Medical Centre Ljubljana and Maribor and the Institute of Oncology.

Payment for acute inpatient care is based on DRG adopted from the Australian system in 2003. Although this DRG system is littered with inconsistencies, no revisions were ever introduced. For example, any major pulmonary resection in UMC Ljubljana (pneumonectomy, lobectomy, or segmental resection) without regard to the technique (VATS or open) is reimbursed $\$ 6.500$, precisely the same as any minor pulmonary resection $(\$ 6,500)$, while an esophagectomy is reimbursed $\$ 14,000$. Half of the reimbursed amount is typically spent on the general running costs of the hospital and $30 \%$ on the salaries of medical personnel. The remaining $20 \%$ is insufficient to cover the costs of disposable materials and drugs, especially when minimally invasive techniques are used. To prevent excessive deficits, hospital management in the past decades continuously looked for ways to limit the use of disposable materials, thus slowing down the adoption of VATS.

\section{Medical personnel}

Slovenia has fewer physicians per capita than both the EU and the Central and Eastern European countries, and new trainees are not adequately replacing the number of health professionals retiring. There is also a net deficit of nurses with university and college degrees.

There are eleven active board-certified thoracic surgeons in Slovenia (six in UMC Ljubljana, three in UMC Maribor, two at Golnik), and four thoracic surgery residents (two in Ljubljana and one in Maribor and Golnik).

After Slovenia separated from the Federal Republic of Yugoslavia in 1991, the lack of adequate healthcare funding demanded substantial savings that resulted in a more than a decade-long hospital employment restriction when new doctors or nurses were only employed to replace the retired. As a result, a considerable generation gap was created within the community of thoracic surgeons. When six thoracic surgeons retired recently, a single fully active thoracic surgeon was left in the country in the above 50-year age group.

So far, no immigrant thoracic surgeon was ever employed in Slovenia. Slovenian language competency level of $\mathrm{C} 1$ (upper-intermediate) is required for all immigrant doctors. This presents a significant challenge even to doctors fluent in any of the languages of the republics of former Yugoslavia, which share many similarities with the Slovenian language.

On the other hand, nearby countries such as Austria, Germany, Switzerland, and Arabic countries such as Saudi Arabia or the United Arabic Emirates are actively recruiting medical personnel from Balkan countries, providing them a better working environment, higher salaries, and many benefits such as housing, additional education, and language assistance. As a result, one thoracic surgeon moved from UMC Maribor to Basel (Switzerland) in 2016.

\section{Lung cancer}

Lung cancer is currently the $2^{\text {nd }}$ most common cancer in male patients and the fourth most common cancer in female patients in Slovenia. The incidence rate of lung cancer in the male population is 90 new cases per 100,000 inhabitants. The number stabilized in the 1990s after decades of constant increase, whereas the incidence of lung cancer in the female population is still growing and is currently at 45 new cases per 100,000 inhabitants (2).

All discovered lung cancer cases are presented to a multidisciplinary tumor board, where individualized therapy is discussed.

During 2018 and 2020, a total of 5,488 new lung cancer patients were discovered in Slovenia, $933(17 \%)$ with stage I, 1,592 (29\%) with stage II and III, and 2,963 (54\%) with stage IV disease. Most patients (27\%) did not receive any specific treatment, $23 \%$ were treated by radiation alone, $17 \%$ received chemo and radiation, and $19 \%$ were treated by surgical resection. Out of a total of 1,006 major pulmonary resections during those 3 years, $436(43.3 \%)$ were performed in UMC Ljubljana, 317 (31.5\%) at Golnik, and $253(25.1 \%)$ in UMC Maribor.

In the past 20 years, lung cancer surgery in Slovenia, similar to the rest of the world, underwent a significant transformation (Figure 2):

* The rate of pneumonectomies dropped from 
$38.7 \%$ in 1988 (3) to less than $5 \%$ and the rate of exploratory thoracotomies dropped from $9.4 \%$ in 1998 and $6.3 \%$ in 2002 to almost inexistence;

* The average age of surgically treated patients increased from 56.4 years in 1988 to 62.0 years in 2002 and 65.5 years in 2018 without any significant influence on 30-day postoperative mortality (still under $1 \%)$;

* Hospital stay was decreased significantly by the

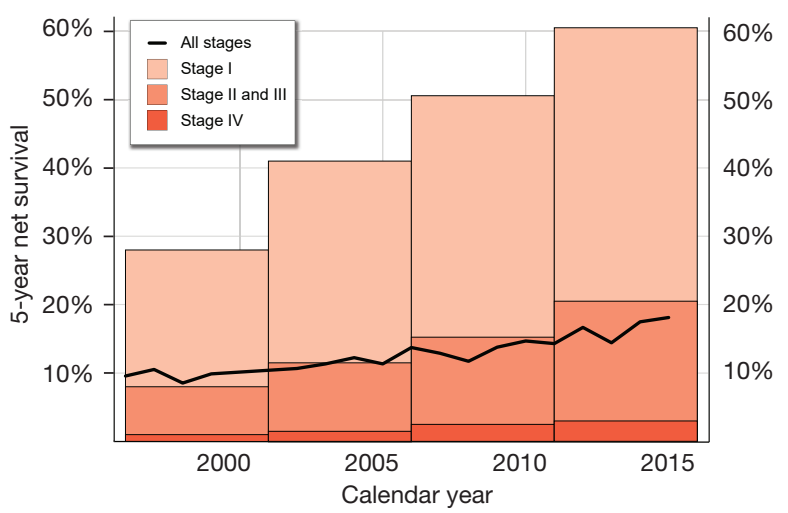

Figure 2 Time trend of 5-year net survival of lung cancer, Slovenia 1996-2016. transition from posterolateral to muscle-sparing thoracotomy to widespread adoption of VATS in the past decade.

Together with more efficient preoperative diagnostics with endobronchial ultrasound (EBUS) and positron emission tomography (PET) imaging introduced in 2007, this led to significantly improved 5-year survival of lung cancer patients (15.9\% in 2015), although it is still approximately $3-4 \%$ lower than top European countries (Figure 3).

Adjuvant chemotherapy is currently given to surgically resected patients younger than 75 -year with stage IIA disease or higher. Trimodality treatment, including surgery, is mainly limited to patients with a Pancoast tumor and considered for patients with excellent performance status and a good response to preoperative nonsurgical treatment (4).

No systematic lung cancer screening program currently exists in the country, neither is it planned to be implemented by the National Institute of Public Health in the following years, even though approximately half of the surgically treated lung cancers are entirely asymptomatic and are discovered by a computed tomography (CT) scan performed for another reason.

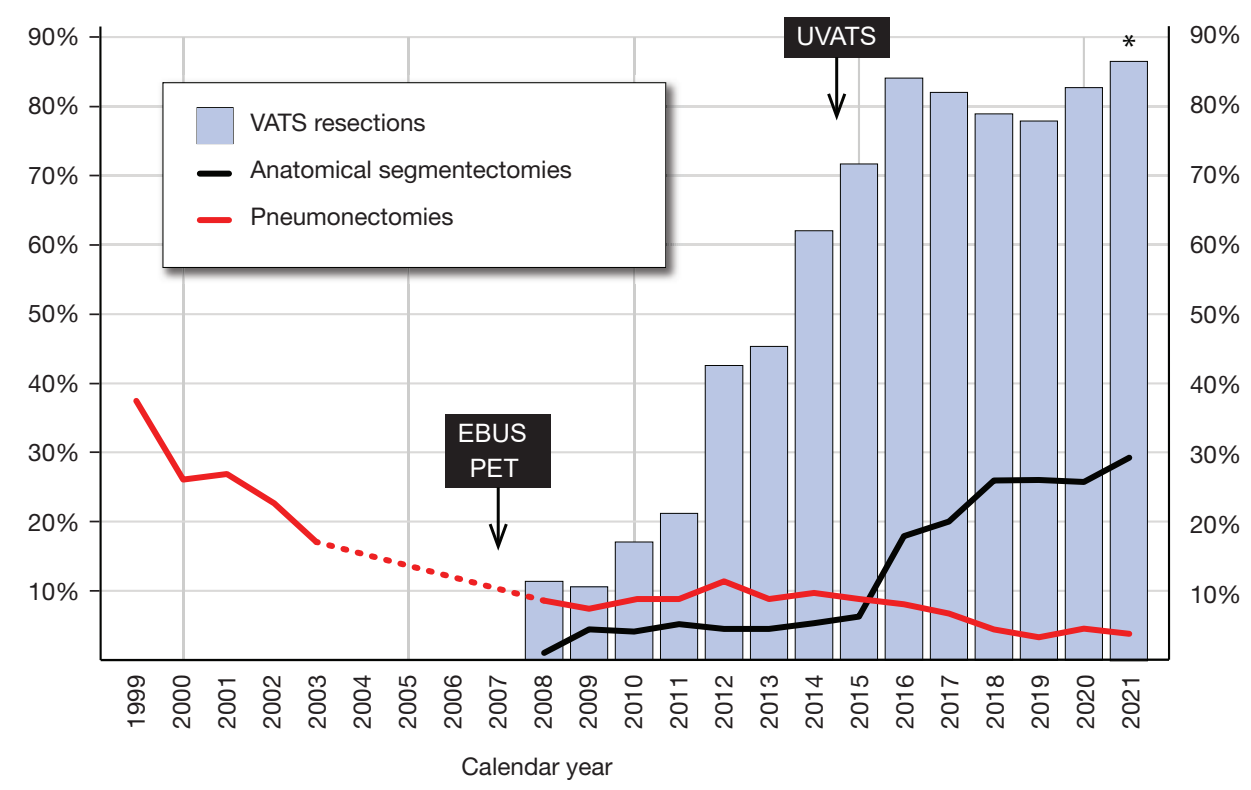

Figure 3 VATS resections, anatomical segmental resections, and pneumonectomies in UMC Ljubljana during the 1999-2021 period as a percentage of all major pulmonary resections. *, data until October 2021. UVATS, uniportal VATS; EBUS, endobronchial ultrasound; PET, positron emission tomography; VATS, video-assisted thoracoscopic surgery; UMC, university medical centers. 


\section{VATS}

Slovenia was the first country in South-eastern Europe to adopt VATS to treat lung cancer and other malignant diseases. VATS major pulmonary resections were introduced to UMC Ljubljana in 2008. Initially, only one surgeon utilized this method, while others were mainly convinced that VATS is not an appropriate approach to treat malignant diseases: due to two unsuccessful cases 10 years earlier (5).

Despite that, the VATS adoption rate in UMC Ljubljana climbed steadily to reach $70 \%$ in 2015 when the new Uniportal VATS (UVATS) almost instantly replaced the old anterior 3-port VATS technique. Over $80 \%$ of all major pulmonary resections, including broncho-vascular sleeve resections, are performed utilizing VATS. Enhanced recovery protocols were also implemented, and more than half of the patients can now be discharged home by postoperative day 2 (6).

After successfully introducing VATS lobectomies to Slovenia, UMC Ljubljana has also played an important role in spreading the technique to Southeastern Europe. Many thoracic surgeons from neighboring countries visited the hospital to learn the technique. During the 2011-2015 period, 12 VATS lobectomy workshops, two international conferences, and two live video transmissions were organized in Ljubljana. Live surgeries were also performed in Poland, Bulgaria, Serbia, Bosnia, and Greece.

Estimated Slovenian nationwide VATS utilization in lung cancer is currently around 60\%. UMC Maribor performed their first VATS lobectomy in 2012, and their preferred approach is currently two-port VATS. Anterior 3-port VATS approach is utilized at Golnik.

\section{Lung transplantation}

Slovenia has a unique advantage in the field of transplantation with a large university hospital, UMC Ljubljana, carrying out all organ transplants and taking care of all recipients. Since 2000, Slovenia has been a full member of the Eurotransplant, a large international collaborative network covering 137 million inhabitants.

The lung transplantation program (LTx) was first introduced in 1997 by a twinning agreement with Allgemeine Krankenhaus (AKH) in Vienna. From 1997 to 2019, a total of 70 Slovenian patients were transplanted in Austria.

Although a single LTx was performed in UMC Ljubljana already in 2003, this single case exposed the lack of dedication and training necessary for the LTx program to continue.

A new team then restarted the program in 2018 with the first double LTx. With 4.81 LTx per million inhabitants in 2019 , Slovenia reached $17^{\text {th }}$ place worldwide (7). In 2020 the first pediatric LTx was performed, and the number of LTx increased even further to 7.59 per million inhabitants (Figure 4).

Of the remaining Balkan countries, only Croatia (also a member of Eurotransplant) has an ongoing program of LTx, started in 2021, whereas in the other eight countries, LTx is not available.

\section{Other procedures}

Because of historical reasons and the country's small size, Slovenian thoracic surgeons also deal with areas not necessarily a part of thoracic surgery.

\section{Esophageal surgery}

Slovenian thoracic surgeons are responsible for the entire field of esophageal surgery, treating esophageal cancer and benign diseases such as Zenker's diverticulum, gastroesophageal reflux disease, and giant paraesophageal hernias.

Approximately 90 new esophageal cancer cases are discovered in Slovenia each year (80\% in male patients) (2) and about $20(22 \%)$ of them are treated by surgical resection. Approximately $85 \%$ of the esophageal cancer resections are performed in UMC Ljubljana.

During 10 years (2009 to 2018), a total of 168 resections were performed in UMC Ljubljana in predominantly male patients $(84 \%)$ of an average age of 63.9 years. $36 \%$ of patients had stage I, 19\% stage II, 26\% stage III, and 17\% stage IV disease. $53 \%$ of patients received preoperative chemoradiation. An Ivor-Lewis resection was performed in $78 \%$, McKeown in $19 \%$, and trans-hiatal in $3 \%$ of cases with $6.5 \%$ perioperative mortality and $46 \%$ perioperative morbidity (15\% of complications were related to conduit). A minimally invasive approach was utilized in $37 \%$ of cases. The median survival of the resected patients was 27 months, with $40 \%$ 5-year survival (8).

\section{Interventional endoscopy}

Rigid bronchoscopy and esophagoscopy with biopsy, foreign body removal, balloon dilation for esophageal achalasia, 

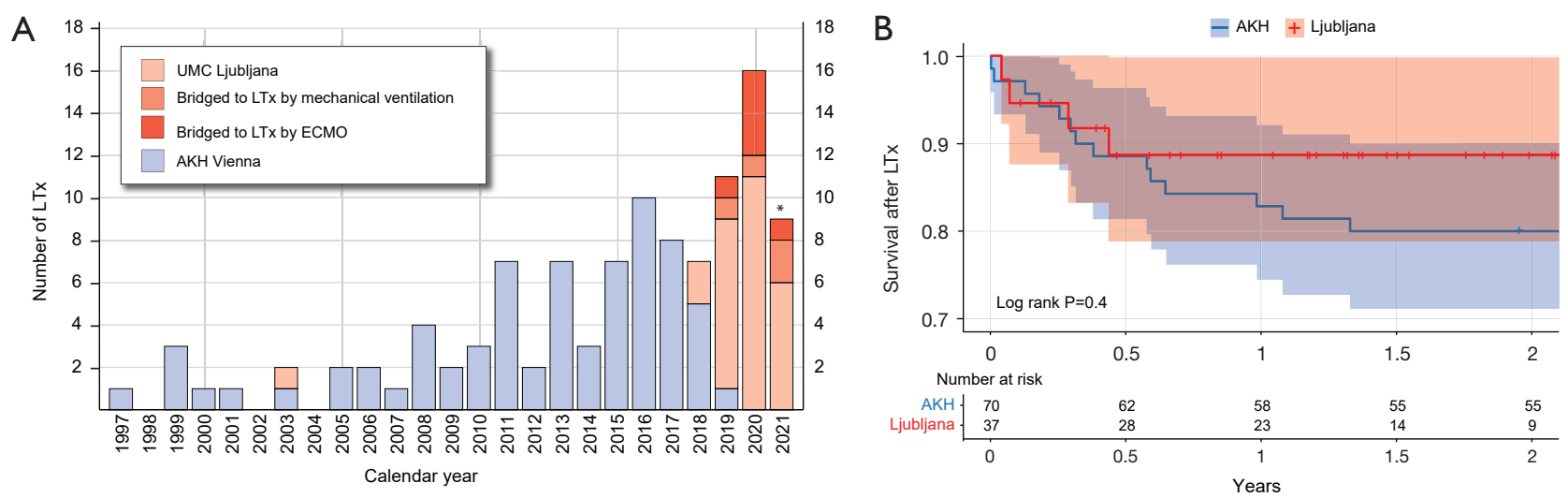

Figure 4 Slovenian lung transplantation program. (A) Number of lung transplantations in Slovenian patients. *, data until October 2021. (B) Short term survival of Slovenian patients following lung transplantation in UMC Ljubljana and AKH Vienna (data until October 2021). LTx, lung transplantation program; UMC, university medical centers; AKH, Allgemeine Krankenhaus.

bougienage for benign esophageal strictures, and airway or esophageal stenting are still predominantly performed by thoracic surgeons and only occasionally by pulmonologists or gastroenterologists $(9,10)$.

\section{Pediatric thoracic surgery}

A unique model of pediatric surgery was established in the 1970s in UMC Ljubljana. The Department of Pediatric Surgery and Intensive Care was organized as a central national pediatric ICU that only employed pediatricians and specialists in pediatric intensive care. All surgical specialties then dedicated their expert surgeons to perform pediatric surgery on top of surgery in adults.

This model was used until 2017, when a separate Department of Pediatric Surgery was established in UMC Ljubljana with a team of dedicated pediatric surgeons that primarily deal with urological and abdominal problems. At the same time, thoracic surgeons are still responsible for a range of pediatric thoracic diseases such as complicated parapneumonic effusions, childhood thoracic tumors, congenital lung malformations, esophageal atresia, congenital diaphragmatic hernias, pediatric fundoplication, and lung transplantation (Table 1) (11).

\section{Thyroid surgery}

In the 1980s, an effort to increase the quality of thyroid surgery in Slovenia centralized thyroidectomies to three centers. Since then, all confirmed malignant thyroids have been referred to the national Oncological Institute, while
Table 1 Summary of pediatric thoracic procedures in Slovenia during 10 years (2011 to 2020)

\begin{tabular}{|c|c|}
\hline Procedure & Count \\
\hline Chest tube placement & 216 \\
\hline VATS pleural debridement & 48 \\
\hline $\begin{array}{l}\text { Tracheoscopy with foreign body } \\
\text { removal }\end{array}$ & 55 \\
\hline $\begin{array}{l}\text { Repair of congenital diaphragmatic } \\
\text { hernia }\end{array}$ & 60 \\
\hline \multicolumn{2}{|l|}{ Repair of esophageal atresia } \\
\hline Primary repair & 68 \\
\hline Delayed long gap repair & 4 \\
\hline \multicolumn{2}{|l|}{ Pulmonary resections } \\
\hline Wedge resections \& biopsies & 63 (16 by VATS, 25\%) \\
\hline Lobectomies \& segmentectomies & 38 (15 by VATS, 40\%) \\
\hline Resection of mediastinal tumors & 22 \\
\hline Fundoplication for GERD & 72 (65 laparoscopic, 90\%) \\
\hline Diaphragm plication & 15 ( 9 by VATS, 60\%) \\
\hline Other & 42 \\
\hline Total & 703 \\
\hline
\end{tabular}

benign goiters have been referred to thoracic surgeons in UMC Ljubljana or UMC Maribor.

Although this significantly improved the results of 

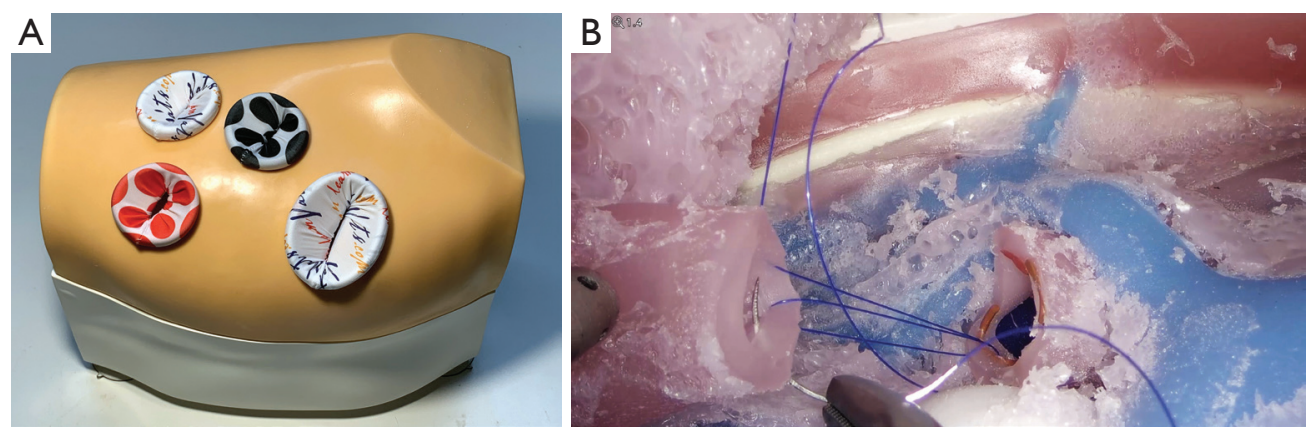

Figure 5 VATS simulator developed in Ljubljana. (A) Artificial chest with wound protectors; (B) bronchial end-to-end anastomosis during simulated VATS sleeve right upper lobectomy. VATS, video-assisted thoracoscopic surgery.

thyroidectomies, the limited capacity of thoracic surgeons to deal with this pathology led to excessively long waiting lists. During the past three decades, the waiting time for thyroidectomy of benign goiter in UMC Ljubljana never dropped below 2 years and is currently estimated at 3.3 years.

\section{Research}

Nine board-certified thoracic surgeons have earned a $\mathrm{Ph} . \mathrm{D}$. degree to date, and three of them are still active in Slovenia. The themes of their doctoral theses covered very diverse topics, from lung cancer and membrane fluidity to growth factors and even biostatistics $(3,12-16)$. The study of malignant pleural effusions and pleurodesis remains the main research topic at UMC Maribor, while the main research focus of UMC Ljubljana has shifted from the research of lung cancer to LTx and VATS, especially VATS education using simulation $(17,18)$.

Since 2015 , a modular VATS simulator has been developed in UMC Ljubljana and is now used worldwide to provide basic and intermediate VATS training (Figure 5). Multiple research projects are ongoing to increase VATS training efficiency and provide formal VATS certification by establishing an efficient and objective method for assessing acquired VATS skills.

Joint research projects with thoracic anesthesiologists investigated the efficiency of regional anesthesia using paravertebral and erector spinae blocks to control intraoperative and postoperative pain for thoracic procedures (19-21).

\section{Conclusions}

Thoracic Surgery in Slovenia is a challenging surgical specialty dealing with a wide range of problems such as lung cancer and other thoracic cancers, diseases of the esophagus, airway surgery, interventional endoscopy, pediatric thoracic surgery, lung transplantation, and even some nonthoracic problems such as surgery of the thyroid and parathyroid.

Slovenian patients certainly have the privilege to have free access to almost everything that contemporary thoracic surgery has to offer, including the most complex and least invasive procedures. On the other hand, both UMCs built in the 1970s cannot provide the most comfortable hospital stay, and waiting times for procedures of lesser priority are unacceptably long.

The success or failure of thoracic surgery in Slovenia has always been dependent on a small number of enthusiastic thoracic surgeons and not so much on the health care system. This fact makes it very sensitive to disturbances since losing a few or even a single key surgeon can negatively affect the entire field. Therefore, a lot of care and effort should be put into selecting and educating new generations of thoracic surgeons.

Slovenian Medical Chamber should soon perform a major revision of the thoracic surgery residency program and create an educational pathway less dependent on the supervisor and local hospital.

\section{Acknowledgments}

Funding: None.

\section{Footnote}

Provenance and Peer Review: This article was commissioned by the Guest Editor (Alan D. L. Sihoe) for the series "Thoracic Surgery Worldwide" published in fournal of Thoracic Disease. The article has undergone external peer 
review.

Peer Review File: Available at https://jtd.amegroups.com/ article/view/10.21037/jtd-21-1172/prf

Conflicts of Interest: The author has completed the ICMJE uniform disclosure form (available at https://jtd.amegroups. com/article/view/10.21037/jtd-21-1172/coif). The series "Thoracic Surgery Worldwide" was commissioned by the editorial office without any funding or sponsorship. The author has no other conflicts of interest to declare.

Ethical Statement: The author is accountable for all aspects of the work in ensuring that questions related to the accuracy or integrity of any part of the work are appropriately investigated and resolved.

Open Access Statement: This is an Open Access article distributed in accordance with the Creative Commons Attribution-NonCommercial-NoDerivs 4.0 International License (CC BY-NC-ND 4.0), which permits the noncommercial replication and distribution of the article with the strict proviso that no changes or edits are made and the original work is properly cited (including links to both the formal publication through the relevant DOI and the license). See: https://creativecommons.org/licenses/by-nc-nd/4.0/.

\section{References}

1. Zupanič Slavec Z (editor). Torakalna kirurgija [Thoracic Surgery]. Zgodovina zdravstva in medicine na Slovenskem [The history of healthcare and medicine in the Slovene lands]. Institute for the History of Medicine, Medical Faculty of Ljubljana, Slovenia, 2018:110-23.

2. Zadnik V, Primic Zakelj M, Lokar K, et al. Cancer burden in slovenia with the time trends analysis. Radiol Oncol 2017;51:47-55.

3. Vidmar S. Vpliv prognostičnih dejavnikov pri reseciranem nemikrocelularnem karcinomu pljuč, stadijev I, II in IIIa, na nadaljni potek bolezni in preživetje. Ljubljana: University of Ljubljana, Medical Faculty, 1996.

4. Zwitter M, Čufer T, Vrankar M, et al. Lung Cancer in Slovenia. J Thorac Oncol 2019;14:1327-31.

5. Eržen J, Bitenc M, Jerman J, et al. Neuspehi endoskopskega operiranja ob pomoči video kamere pri malignih boleznih $\mathrm{v}$ prsnem košu [Failure of videoassisted thoracic surgery for malignant thoracic diseases]. Endoskopska Revija 1997;2:23-6.
6. Gonzalez-Rivas D, Yang Y, Stupnik T, et al. Uniportal video-assisted thoracoscopic bronchovascular, tracheal and carinal sleeve resectionst. Eur J Cardiothorac Surg 2016;49 Suppl 1:i6-16.

7. International Registry in Organ Donation and Transplantation. Final Numbers 2019. 2020. Available online: https://www.irodat.org/img/database/pdf/Newsletter\%20 Dec\%202020\%20.pdf. Accessed 9 Oct 2021.

8. Srpcic M. Impact of muscle mass loss on outcomes after esophagectomy for cancer and comparison of other risk factors. Ljubljana: University of Ljubljana, Medical Faculty, 2021.

9. Terčelj-Zorman M, Turel M, Sok M et al. Dumonov endobronhialni stent [The Dumon endobronchial stent]. Endoskopska Revija 2002;7:118-9.

10. Štupnik T, Hafner T. Treatment of malignant tracheoesophageal fistula by double stenting - case report. Zdravniski Vestnik 2008;77:511-4.

11. Simoncic M, Kopriva S, Zupancic Z, et al. Mediastinal teratoma with hydrops fetalis in a newborn and development of chronic respiratory insufficiency. Radiol Oncol 2014;48:397-402.

12. Crnjac A, Sok M, Kamenik M. Impact of pleural effusion $\mathrm{pH}$ on the efficacy of thoracoscopic mechanical pleurodesis in patients with breast carcinoma. Eur J Cardiothorac Surg 2004;26:432-6.

13. Sok M, Sentjurc M, Schara M. Membrane fluidity characteristics of human lung cancer. Cancer Lett 1999;139:215-20.

14. Srpcic M, Jordan T, Popuri K, et al. Sarcopenia and myosteatosis at presentation adversely affect survival after esophagectomy for esophageal cancer. Radiol Oncol 2020;54:237-46.

15. Štupnik T, Pohar Perme M. Analyzing disease recurrence with missing at risk information. Stat Med 2016;35:1130-43.

16. Hojski A, Leitgeb M, Crnjac A. Release of growth factors after mechanical and chemical pleurodesis for treatment of malignant pleural effusion: a randomized control study. Radiol Oncol 2015;49:386-94.

17. Štupnik T, Dolenšek MI, Mlakar J, et al. Urgent lung transplantation for thymic neoplasm-associated severe constrictive bronchiolitis with bronchiectasis and radiotherapy-induced organizing pneumonia: A case report. Thorac Cancer 2021;12:1757-60.

18. Štupnik T, Stork T. Training of video-assisted thoracoscopic surgery lobectomy: the role of simulators. Shanghai Chest 2018;2:52. 
19. Gams P, Danojević N, Bitenc M, et al. Continuous erector spinae plane block as part of opioid-sparing postoperative analgesia after video-assisted thoracic surgeries: Series of 4 cases. Indian J Anaesth 2020;64:516-9.

20. Novak-Jankovic V, Milan Z, Potocnik I, et al. A prospective, randomized, double-blinded comparison between multimodal thoracic paravertebral bupivacaine and levobupivacaine analgesia in patients undergoing lung surgery. J Cardiothorac Vasc Anesth 2012;26:863-7.

21. Pintaric TS, Potocnik I, Hadzic A, et al. Comparison of continuous thoracic epidural with paravertebral block on perioperative analgesia and hemodynamic stability in patients having open lung surgery. Reg Anesth Pain Med 2011;36:256-60.

Cite this article as: Štupnik T. Thoracic surgery in Slovenia. J Thorac Dis 2022;14(6):2326-2334. doi: 10.21037/jtd-21-1172 